\title{
Analysis of Students' Error in Learning of Trigonometry Among Senior Secondary School Students in Zaria Metropolis, Nigeria.
}

\author{
${ }^{1}$ Mu'awiya Haruna Usman, ${ }^{2}$ Muhammad Mukhtari Hussaini \\ Department of Mathematics, Federal College of Education Zaria, Nigeria \\ Depertment of Mathematics, Aminu Saleh College of Education Azare, Nigeria
}

\begin{abstract}
The purpose of the study was to determine the students' error in learning trigonometry A total of 80 Senior Secondary 2 mathematics students randomly selected from two private schools in Zaria with a mean age of 17 constituted the sample size for the study. The Mathematics achievement tests (MAT) and Trigonometrical diagnostic test (TDT) were used as the instruments of this study that included two components: the use of formula and right-angled method. Diagnostic interview was also used to identify at which level students' errors occur in solving problems. The type of error is based on Newman Error Hierarchy Model that includes reading type error, comprehension, transformation, process skill, and encoding error. Data was analyzed using descriptive statistics: percentage and frequency. The study found out among others that most students make error in transformation and process skill in solving problems in trigonometry. There was no error found in reading. The number of students who made encoding error and carelessness was small. The students' error in solving trigonometrical problems was due to their weaknesses in basic arithmetical operations. The implication of the study was highlighted and recommendations were made based on findings.
\end{abstract}

Keywords: Trigonometry, Comprehension error, Transformation error, Process skill error

\section{Introduction}

Trigonometry is an area of mathematics that students believe to be particularly difficult and abstract compared with the other subjects of mathematics. It is an area that very few students like and succeed at, and which most students hate and struggle with. Trigonometry is often introduced early in junior secondary with most textbooks traditionally starting with naming sides of right-angled triangles. Students need to see and understand why their learning of trigonometry matters (Gur, 2009). Many studies concerned with mathematics education explain that students have misconceptions and make errors. These errors in solving mathematical problems often occur directly or inadvertently ranging from writing to oral and even computation (Zakaria, 2010). These situations grow out of learning complexities (Ryan \& Williams, 2000). Of late, a few researchers have mentioned students' misconceptions, errors, and related to these, learning complexities about trigonometry (Delice 2002; Orhun, 2013).Fi (2003) states that much of the literature on trigonometry has focused on trigonometric functions. A few researchers studied more specific issues in trigonometry such as simplification of trigonometric expressions and metaphors (Delice, 2002; Weber, 2005; Presmeg 2006, 2007). Brown (2006) studied students' understanding of sine and cosine. She reached a framework, called trigonometric connection. The study indicates that many students had an incomplete or fragmented understanding of the three major ways to view sine and cosine: as coordinates of a point on the unit circle, as a horizontal and vertical distances that are graphical entailments of those coordinates, and as ratios of sides of a reference triangle. Orhun (2015) studied the difficulties faced by students in using trigonometry for solving problems in trigonometry. Orhun (2015) found that the students did not develop the concepts of trigonometry certainly and that they made some mistakes. However, many errors are committed due to the mechanical application of a rule in trigonometry exercises. The mastery of basic mathematical concept is an essential step in concept development. When basic concepts are not learnt at early stage, the learning process of an advanced stage becomes more difficult. This occurs because the learning process in mathematics categorized as hierarchical learning processes are broadly interrelated (Liew \& wan Muh'd, 1991). During the process of teaching and learning mathematics, students will face many obstacles because problem solving in mathematics is a skill that is very complex. Sometimes students know how to answer the question stated, but careless in computation.

The conceptual framework that is used in this study is based on Newman Error Hierarchical Model. The model of error investigation proposed by Newman (1977) has proved to be a reliable model for mathematics teachers. The framework has six types of errors: reading error, comprehension, transformation, process skill, encoding error and carelessness. The Newman Error Hierarchical Model is suitable to be used in identifying students' error in mathematics. This model has the hierarchy that classifies types of error based on the problem solving level done by students. According to Clements and Ellerton (1996), Newman used the word "hierarchy" because she reasoned that failure at any level of the sequence prevents students from obtaining 
satisfactory solutions. Prakitipong and Nakamura (2006) pointed out, that in the process of problem solving there are two kinds of obstacle that hinder students from arriving at correct answers:

(a) Problems in linguistics fluency and conceptual understanding that correspond with level of simple reading and understanding meaning of problems, and

(b) Problems in mathematical processing that consists of transformation, process skills, and encoding answers.

This classification implies that the students have to interpret the meaning of the question before they proceed to mathematical processing to obtain appropriate answer. It is in the light of the above that the study set out to analyze students' error in learning of trigonometry among senior secondary school students.

\section{Purpose of the study}

The main purpose of the study was to analyze students' error in learning of trigonometry which focused on the manipulation of trigonometrical ratios using formula and the right-angled triangle. Specifically, the study sought to:

1. Determine the extent to which individual students commit error in the learning of trigonometry.

2. Find out the possible categorization of these errors in the learning of trigonometry.

\section{Research question}

Three research questions were posed for this study:

i. To what extent will individual students' error influence the learning of trigonometry?

ii. What are the possible categorization of these errors in the learning of trigonometry?

iii. What are the student's answers that help us explore the students' thinking and reflection about learning of trigonometry?

\section{Methodology}

The population for the study consists of all senior secondary schools in Zaria, Nigeria. Zaria and its environ is made up of over twenty senior secondary schools with a population of over seven thousand (7000) students.The government funded schools unlike the privately own ones are non-coeducational. Apart from having qualified teachers, the students offer mathematics as a major subject. The private schools were therefore considered appropriate for the study and it is from this population that the study sample was drawn.

\section{Sample}

The study was conducted using 80 senior secondary (SS2) students randomly drawn from two non-government funded (private) secondary schools in Zaria metropolis in Nigeria. The mean age of the students was 17 years.

\section{Instrumentation}

The study used a set of trigonometrical diagnostic test (TDT) questions designed by the investigator to identify type of error committed by students. Prior to the commencement of the study, the questions were subjected to face and Pearson's product moment content validated test respectively. The reliability coefficient as computed from Pearson's product moment correlation for Trig. diagnostic test (TDT) was $r=0.85$. The value suggest that the test question were reliable and as such would test what it was designed for. In addition, content and face validity of the instrument was carried by the investigator who is a specialist in mathematics and other specialists in cognate field compared to the overall objective of the curriculum.

Prior to the investigation, the respondents were subject to general mathematics achievement test. The primary objective of the MAT items was to categorize the students into high achievers (A) for those that scored $65 \%$ and above and achievers (B) for those that scored 50-64\%. This is shown in Table 1.

The investigator also interviewed the respondent based on the modified procedure of Newman Error Hierarchical Model from the outcome of the written test. The questions for the respondent included:

i) Can you read the problem? (Reading level)

ii) What does the question ask you to do? (Comprehension level)

iii) What do you use to solve the question? (Transformation level)

iv) Can you show me the working steps that you have used in order to find the answer? (Process Skills)

v) Tell me what is your answer? (Encoding)

Table 1: Distribution of Students According to Different Achievement Levels

\begin{tabular}{|lcccc|}
\hline Profile & $\begin{array}{c}\text { High Achievers } \\
\text { (A) }\end{array}$ & $\begin{array}{c}\text { Achievers } \\
\text { (B) }\end{array}$ & Total & Percentage (\%) \\
\hline Male & 22 & 20 & 42 & \\
Female & 20 & 18 & 38 & \\
& & & & \\
\hline Total & 42 & 38 & 80 & \\
\hline
\end{tabular}


Table 2: Number of Items (TDT) according to Skills

\begin{tabular}{|c|c|c|c|}
\hline Solving method & Skill & em number & Number of Item \\
\hline Trig Ratio by formula & $\begin{array}{l}\text { Solving trigonometrical } \\
\text { Ratio using formula }\end{array}$ & $1-7$ & 7 \\
\hline Trig Ratio by right-an & $\begin{array}{l}\text { led Solving trigonometrical } \\
\text { Ratio using the right-angled } \\
\text { Triangle }\end{array}$ & led $1-7$ & 7 \\
\hline
\end{tabular}

Table 3: Error in solving Trig Problem by right-angled triangle

Frequency of Error

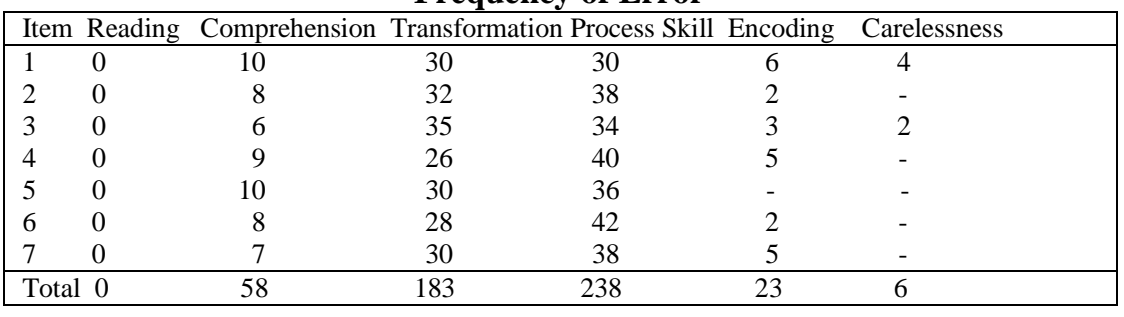

Table 4: Error in solving Trig Problem by use of formula

Frequency of Error

\begin{tabular}{|llccccc|}
\hline Item & Reading & Comprehension & Transformation Process Skill & Encoding & Carelessness \\
\hline 1 & 0 & 5 & 25 & 40 & 6 & 4 \\
2 & 0 & 6 & 28 & 41 & 3 & 2 \\
3 & 0 & 5 & 25 & 45 & 4 & - \\
4 & 0 & 6 & 20 & 48 & 5 & - \\
5 & 0 & 7 & 23 & 42 & 6 & 2 \\
6 & 0 & 5 & 24 & 44 & 5 & - \\
7 & 0 & 4 & 27 & 43 & 4 & 2 \\
\hline Total & 0 & 38 & 172 & 303 & 33 & 10 \\
\hline
\end{tabular}

\section{Discussion}

The most frequent errors made by student in solving problems in trigonometry include comprehension error, transformation error and process skill error. Most comprehension errors occur when students do not understand how to approach a given trigonometrical problem from the concept. Students' often misunderstand the demand of the question. This may be due to the lack of emphasis by teachers in teaching the simplification of concepts as they appear. It may also be due to rote learning on the part of the learner. Gur (2009) noted that errors committed by students in learning trigonometry may useful for the teacher in evaluating his teaching so as to be able to correct the students as appropriate. Therefore, teachers must ensure that the teaching of mathematical concepts must be balanced with the arithmetic skills. The findings from present study is consistent with previous reports (Delice, 2002; Intanku 2003; Weber, 2005; Brown, 2006, Zakaria, 2010).

The error type in transformation occurred during computation process especially during multiplication. This takes place due to computation problem especially among achievers. Most students make error at the process skill level especially in the manipulation of trig ratios using formula. For example in item 3 the students were required to find cosec $\mathrm{A}$ given that Tan $\mathrm{A}$ is $5 / 12$ it was found most students who got the item by the use of right-angled triangle method could not replicate same answer using the formula as a result of appropriate placing and manipulation. The findings of the study support the research of Norasiah (2002) who noted that most average students face difficulty in performing trigonometrical operations.

The error in process skill seems more pronounced in the use of formula than the right-angled triangle method. This error may be due to the fact that students failed to understand and describe what is required by the questions. Most students did not manage to perform the operation especially when numerical values are involved. This results in failure to solve the problems. Results of this study concurred with the findings of Norasiah (2002) in which problematic students failed to translate mathematical problems into mathematical form and also having problem in understanding the special terms in mathematics. This failure may be caused by lack of emphasis by teachers on understanding the language of trigonometry and the skills needed by the students. Orhun (2015) puts the buck of students error in trigonometry at the teachers table and noted that when trigonometry is taught via teacher-active method with constant memorizing of the ready knowledge and repeating them will make the students learn trigonometry effectively. For example, emphasis on the trigonometrical acronym of SOHCAHTOA and their reciprocals as well as the foundational Pythagoras theorem will go a long way in preparing the students for a logical and systematic learning of trigonometry. This in the 
authors view is probably why the students write the answers that are at variance with concepts and method learnt in class.

Results of this study are in line with the research findings of Liew and Wan Muhammad (1991) who observed that emphasis on algorithmics skills without explanation on the concept or principle are the factors that cause difficulties in mathematics and by extension poor achievement in trigonometry.

\section{Conclusion and Recommendations}

The results of this study revealed that most error committed by students irrespective of the method used are transformation errors and process skills errors. It further shows that generally, students irrespective of different cognitive ability are susceptible to error in solving problems in trigonometry.

In view of the findings above, it is therefore recommended that:

1. Teachers as facilitator of the teaching-learning process should encourage the learners to concentrate on one point at a time and proceed stepwise in a logical manner to reduce attendant difficulty faced in trigonometry.

2. Teacher should make trigonometry lessons exciting by encouraging group work with frequent activitybased demonstrations so as to demystify the difficulty encountered in problems involving trigonometry.

3. Learners should be given enough opportunities to do regular problem exercises as this will go a long way in assisting them and increasing their reasoning skills.

4. This study should be repeated with other similar mathematically based concepts so as to compare findings.

Appendix A: Trigometrical Diagnostic Test (TDT)

1. Show that $\operatorname{Sin}^{2} \mathrm{~A}+\operatorname{Cos}^{2} \mathrm{~A}=1$

2. Given that $\operatorname{Sin} A=0.80$, Find $\tan A$

3. Find Cosec $\mathrm{A}$ when $\tan \mathrm{A}$ is $5 / 12$

4. Given that $\operatorname{Cos} 60^{\circ}=0.5$, what is $\operatorname{Cosec} 30^{\circ}$ ?

5. Find Cot B when $\operatorname{Sec} B=p / q$

6. Simplify $(\operatorname{Sin} \mathrm{A}+\operatorname{Cos} \mathrm{A})^{2}$

7. Find Tan $\mathrm{A}$ when $\operatorname{Cosec} \mathrm{A}=17 / 5$

\section{References}

[1]. Brown, A.S. (2006). The trigonometric connection: students' understanding of sine and cosine. Proceedings 30th Conference of the International Group for the Psychology of Mathematics Education, 1, p.228. Prague: PME30.

[2]. Clements, M.A. \& Ellerton, N.F. (1996).The Newman procedure for analysing errors on written mathematical tasks. Retrieved January12, 2010, from http://compasstech.com.au/ARNOLD/ PAGES/newman.htm

[3]. Delice, A. (2002). Recognizing, recalling and doing in the 'simplification' of trigonometric expressions. The $26^{\text {th }}$ Annual Conference of the International Group for the Psychology of Mathematics Education (PME26), the School of Education and Professional Development at the University of East Anglia, Norwich: England, 1, 247.

[4]. Fi, C. (2003). Preservice Secondary School Mathematics Teachers' Knowledge of Trigonometry: Subject Matter Content Knowledge, Pedagogical Content Knowledge and Envisioned Pedagogy. Unpublished PhD Thesis, University of Iowa: USA.

[5]. Gur, H.( 2009 ) Trigonometry Learning. New Horizons in Education, 57(1), 67- 80.

[6]. Intanku, S. S. (2003).Diagnosis for the type of error in differentiation. Unpublished Master of Education Research Project. Universiti Kebangsaan Malaysia.

[7]. Liew, S.T. \& Wan Muhamad Saridan Wan Hasan. (1991). Understanding and minimizing difficulty in learning mathematics Berita Matematik, 38, 22-29

[8]. Newman, M.A. (1977). An analysis of 6th grade pupils' errors on written mathematical task. Dlm. Clements, M.A. \& Foyster, J. (Eds). Research in Mathematical Education in Australia: 239-258.

[9]. Norasiah, A. (2002). Error type diagnosis in learning simultaneous equation. Unpublished Master of Education Research Project, Universiti Kebangsaan Malaysia.

[10]. Orhun, N. (2013) The effects of learning styles on high school students' achievement on a mathematics course. Educational Research and Reviews,8(14),1158-1165.

[11]. Orhun, N. (2015) Students'Mistakes And Misconceptions On Teaching Of Trigonometry. 1st ed. Web. 14 Jan. 2015.

[12]. Prakitipong, N. \& Nakamura, S. (2006).Analysis of mathematics performance of Grade 5 students in Thailand using Newman procedure. Journal of International Cooperation in Education, 9(1), 111-122.

[13]. Presmeg, N. (2006). "A semiotic view of the role of the imagery and inscriptions in mathematics teaching and learning". Proceedings 30th Conference of the International Group for the Psychology of Mathematics Education, 1, 19-34. Prague: PME30.

[14]. Presmeg, N. (2007). "The power and perils of metaphor in making internal connections in trigonometry and geometry" CERME5, 22-26 February 2007 Larnaca, Cyprus.

[15]. Ryan, J. T. \& Williams, J. S.(2000). Mathematical discussions with children: exploring methods and misconceptions as a teaching strategy. Manchester: University of Manchester.

[16]. Weber, K. (2005). Students' understanding of trigonometric functions. Mathematics Education Research Journal. 17(3), 91-112.

[17]. Zakaria, E.(2010) Analysis of Students' Error in Learning Quadratic Equations. International Education studies. 3(3) 105-110. 